\title{
Postoperative Coronary Artery Spasm after Mitral Valve Replacement and Cox-Maze IV Procedure: a case report
}

\section{Qianlei Lang}

Sichuan University West China Hospital

\section{Chunyan Li}

Sichuan University West China Hospital

Chaoyi Qin

Sichuan University West China Hospital

Wei Meng ( $\sim$ MeWe1111@163.com )

Sichuan University West China Hospital

\section{Case report}

Keywords: Mitral valve replacement, Cox-Maze IV, Coronary artery spasm, Case report

Posted Date: March 26th, 2021

DOI: https://doi.org/10.21203/rs.3.rs-348012/v1

License: (9) This work is licensed under a Creative Commons Attribution 4.0 International License.

Read Full License

Version of Record: A version of this preprint was published at The Heart Surgery Forum on August 25th, 2021. See the published version at https://doi.org/10.1532/hsf.4005. 


\section{Abstract}

Background: Little case was reported about coronary artery spasm after a mitral valve replacement and concomitant Cox-Maze IV procedure. We reported a case of an adult male who develop right coronary artery (RCA) spasm after a mitral valve replacement with tricuspid valve repair and Cox-Maze IV procedure.

Case presentation: A 66-year-old male, complaining progressive exertional shortness of breath, was diagnosed as severe mitral stenosis, moderate tricuspid regurgitation, complete right bundle branch block and persistent atrial fibrillation (AF) in our clinic. The patient underwent elective mitral valve replacement, tricuspid valve repair and Cox-Maze IV procedure. $4 \mathrm{~h}$ after surgery, a 12-lead electrocardiogram (ECG) showed progressive elevation of ST-segment in the avF and III leads and Troponin-T was over 7000 $\mathrm{pg} / \mathrm{mL}$. After $1 \mathrm{~h}$, Troponin-T increased to over $10000 \mathrm{pg} / \mathrm{mL}$ and ECG still showed persisted ST-segment elevation in inferior leads. Emergent angiography was performed and intra-coronary administration of nitroglycerin completely relieved the spasm.

Conclusions: Potential risks of coronary injury after valvular surgery and Cox-Maze IV procedure need further aggressive investigation and postoperative ischemia should prompt an emergent coronary angiography to identify the cause and apply immediate therapy.

\section{Background}

In the 3 decades since the first Cox-Maze procedure was performed in 1987, surgical treatment for patients with AF has seen extensive advances. Cox-Maze IV was more frequently performed as a concomitant procedure during other cardiac surgeries, especial involving in mitral valve diseases. It is reported that radiofrequency catheter ablation was related to coronary arteries, including spasm, strictures and stenosis(1). However, little case was reported about coronary artery spasm after a mitral valve replacement and concomitant Cox-Maze IV procedure for persistent AF. We reported a case of an adult male who develop RCA spasm after a mitral valve replacement with tricuspid valve repair and CoxMaze IV procedure.

\section{Case Presentation}

A 66-year-old male, complaining progressive exertional shortness of breath, was diagnosed as severe mitral stenosis, moderate tricuspid regurgitation, complete right bundle branch block and persistent AF in our clinic. The patient underwent elective mitral valve replacement, tricuspid valve repair and Cox-Maze IV procedure using the Cardioblate $\rightarrow$ LP system (Medtronic, Minneapolis, Minnesota, USA). Pre-operative angiography showed mild stenosis of RCA and left anterior descending artery, and transthoracic echocardiography showed deteriorated left ventricular function with $40 \%$ ejection fraction.

The surgery was uneventful and total aortic clamp time was $82 \mathrm{~min}$. Cardioplegia was perfused through aortic root every $15-20 \mathrm{~min}$ and the core temperature was cooled down to $34^{\circ} \mathrm{C}$. During the removal of 
cardiopulmonary bypass, the ECG monitor showed a $90-100 \mathrm{bpm}$ sinus rhythm alternated with a pacing rhythm of $80 \mathrm{bpm}$.

The patient was transferred to our intensive care unit (ICU) with junctional rhythm. $4 \mathrm{~h}$ after surgery, a 12lead ECG showed progressive elevation of ST-segment in the avF and III leads and Troponin-T was over $7000 \mathrm{pg} / \mathrm{mL}$. Therefore, acute myocardial infarction of inferior wall was highly suspected. Given that myocardial injury of cardiopulmonary bypass and radiofequency ablation, and stable hemodynamic condition, cath lab was informed and re-check of Troponin-T was arranged. After $1 \mathrm{~h}$, Troponin- $\mathrm{T}$ increased to over $10000 \mathrm{pg} / \mathrm{mL}$ and ECG still showed persisted ST-segment elevation in inferior leads (Fig. 1A-D). Although hemodynamic was stable and transthoracic echocardiography showed acceptable left ventricular contraction, emergent angiography was performed in cath lab. Distal part of RCA spasm was found and intra-coronary administration of nitroglycerin completely relieved the spasm (Fig. 1E, F;

Supplementary video 1 and 2). The patient was maintained on nitrates and aspirin after fully discovery. No recurrent elevation of ST-segment and Troponin-T was recorded.

\section{Discussion And Conclusions}

Radiofrequency surgical ablation was commonly used for Cox-Maze procedure and many studies had approved the safety and efficacy. Permanent pacemaker implantation, bleeding and myocardial injury were common complications after Cox-Maze procedure. Coronary artery spasm after valvular surgery and concomitant Cox-Maze IV procedure was rarely reported.

Some studies reported severe coronary artery spasm after catheter radiofrequency ablation. It is wellknown that direct thermal damage from radiofrequency energy or an imbalance in autonomic nervous system activity might take responsibility. It is reported that atrium contained epicardial ganglionated plexuses consist of different patterns of sympathetic and vague nerves, which could cause an imbalance in autonomic nervous system activity under different stress(2). In addition, complete resolution of coronary artery spasm through intracoronary infusion of nitroglycerin helped to rule out the air embolism or thrombosis.

The actual incidence of postoperative coronary artery spasm was basically unknown. In an English literature review, nearly $20 \%$ cases were only suspected as a result of the clinical presentation without coronary angiography(3). In accord with other reports showing that most common postoperative coronary artery spasm happened in the ICU up to $6 \mathrm{~h}$ after surgery, our patient presented with elevations of ST-segment and Troponin-T at $4 \mathrm{~h}$ after the surgery. Given that preoperative angiography showed mild stenosis of both right and left coronary artery, intensive oxidative stress, inflammation and changes of vascular reactivity might result in the postoperative coronary artery spasm(4).

Postoperative coronary artery spasm could be a lethal event and early mortality was high(3). However, once angiography was conducted, direct intracoronary administration of nitrates or calcium channel blockers could be rapidly effective. In conclusion, potential risks of coronary injury after valvular surgery 
and Cox-Maze IV procedure need further aggressive investigation and postoperative ischemia should prompt an emergent coronary angiography to identify the cause and apply immediate therapy.

\section{Abbreviations}

RCA: right coronary artery; AF: Atrial fibrillation; ECG: Electrocardiogram; ICU: Intensive care unit;

\section{Declarations}

\section{Ethics approval and consent to participate}

Not applicable.

\section{Consent for publication}

Written informed consent of clinical detail and image publication was obtained from the patient.

\section{Availability of data and materials}

The authors declare that the data supporting the findings of this study are available within the article and its supplementary information files.

\section{Competing interests}

The authors declare that they have no competing interests.

\section{Funding}

No funding or grant support.

\section{Authors' contributions}

QLL and CYL performed the literature search and wrote the manuscript. CYQ provided and collated the data. WM participated in the revision of the manuscript and provided clinical decision-making. All authors read and approved the final manuscript.

\section{Acknowledgements}

Not applicable.

\section{References}

1. Hishikari $K$, Kuwahara $T$, Takahashi A, Isobe M. Severe coronary artery spasm during radiofrequency ablation for atrial fibrillation. Int J Cardiol 2014;172:e513-5. 
2. Nakagawa H, Scherlag BJ, Patterson E, Ikeda A, Lockwood D, Jackman WM. Pathophysiologic basis of autonomic ganglionated plexus ablation in patients with atrial fibrillation. Heart Rhythm 2009;6:S26-34.

3. Pragliola C, Gaudino M, Farina P, Massetti M. Postoperative coronary artery spasm after mitral valve replacement. Int J Surg Case Rep 2015;8C:185-8.

4. Ruel M, Khan TA, Voisine P, Bianchi C, Sellke FW. Vasomotor dysfunction after cardiac surgery. Eur J Cardiothorac Surg 2004;26:1002-14.

\section{Figures}




\section{A. post-operative in ICU}

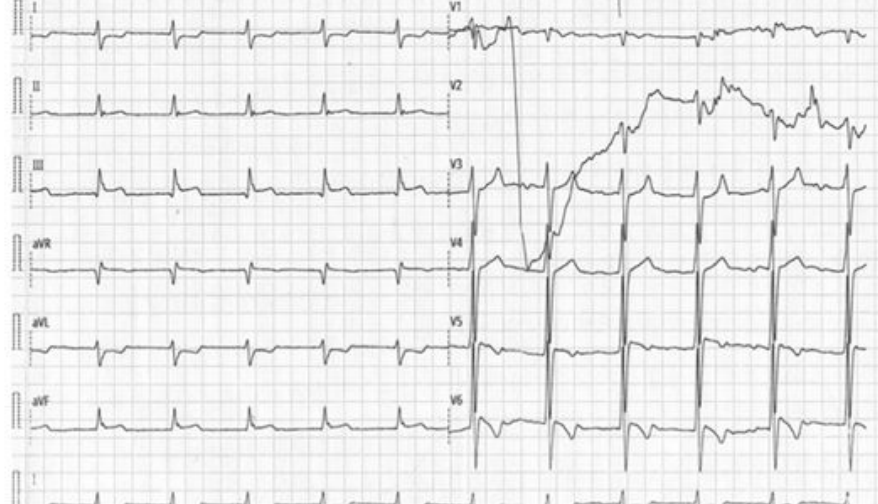

\section{C. post-operative $5 \mathrm{hrs}$ in ICU}
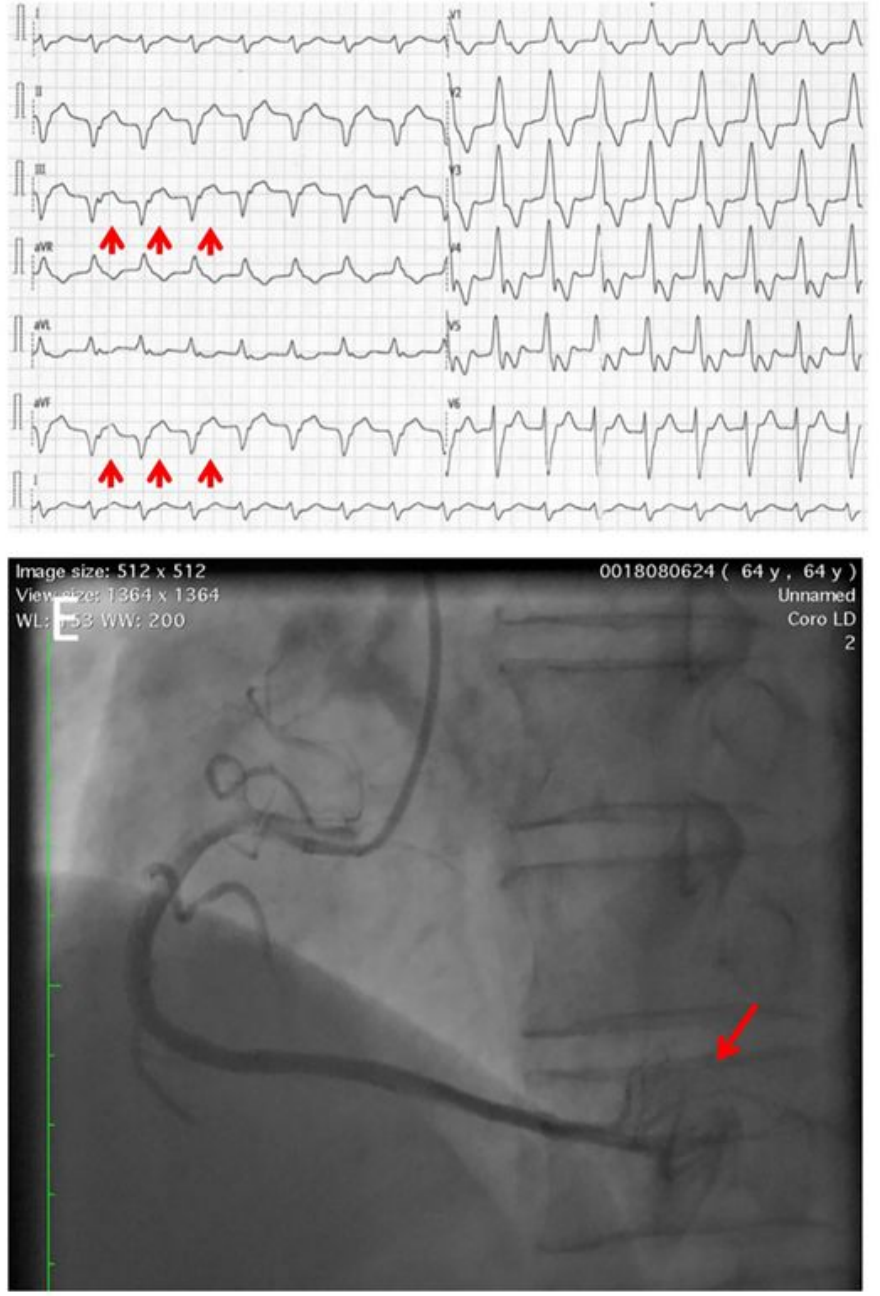

\section{B. post-operative $4 \mathrm{hrs}$ in ICU}

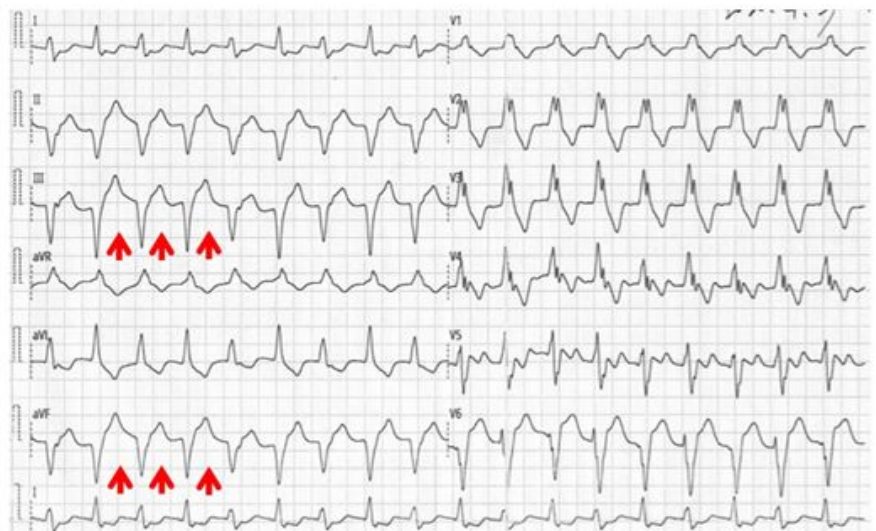

\section{D. post-angiography in ICU}
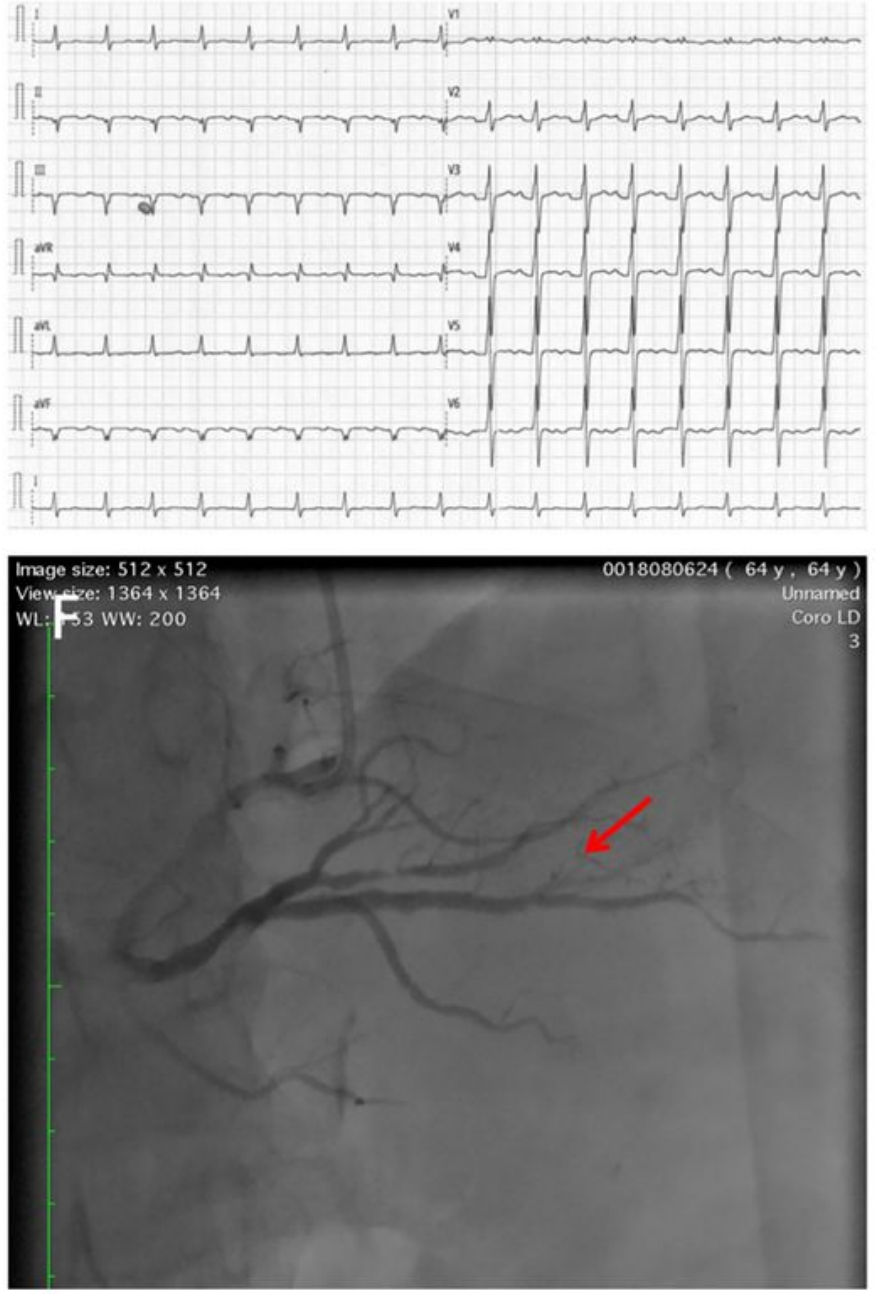

\section{Figure 1}

Dynamic variants of ECG and angiography images. (A) Immediate 12-leads ECG was performed when the patient was transferred into our ICU and showed junctional rhythm. (B, C) 4 hours after surgery, ECG showed elevation of ST-segment of inferior leads and 1 hour later, progressive elevation of inferior leads was identified (arrows). (D) After emergent angiography and intracoronary administration of nitroglycerin, ECG showed normal sinus rhythm. (E) Emergent angiography showed distal part of right coronary spasm 
(arrows). (F) Intracoronary administration of nitroglycerin relieved the spasm (arrows) and angiography showed only mild stenosis of distal part of right coronary artery, which was as the same as the preoperative angiography.

\section{Supplementary Files}

This is a list of supplementary files associated with this preprint. Click to download.

- Supplementaryvideo1.mp4

- Supplementaryvideo2.mp4

- carechecklist.docx 